\title{
Influence of proximal box elevation on the marginal quality and fracture behavior of root-filled molars restored with CAD/CAM ceramic or composite onlays
}

\author{
Ilgenstein, Irina ; Zitzmann, Nicola U ; Bühler, Julia ; Wegehaupt, Florian J ; Attin, Thomas ; Weiger, \\ Roland ; Krastl, Gabriel
}

\begin{abstract}
OBJECTIVES This study investigated the influence of proximal box elevation (PBE) with composite resin when applied to deep proximal defects in root-filled molars with mesio-occluso-distal (MOD) cavities, which were subsequently restored with computer-aided designed/computer-aided manufacturing (CAD/CAM) ceramic or composite restorations. MATERIALS AND METHOD Root canal treatment was performed on 48 human mandibular molars. Standardized MOD cavities were prepared with the distal box located $2 \mathrm{~mm}$ below the cemento-enamel junction (CEJ). The teeth were randomly assigned to one of four experimental groups $(n=12)$. In groups $\mathrm{G} 1$ and $\mathrm{G} 2$, the distal proximal box was elevated up to the level of the CEJ with composite resin (PBE). No elevation was performed in the remaining two groups (G3, G4). CAD/CAM restorations were fabricated with feldspathic ceramic (Vita Mark II, CER) in groups G1 (PBE-CER) and G3 (CER) or with resin nano-ceramic blocks (Lava Ultimate, LAV) in groups G2 (PBE-LAV) and G4 (LAV). Replicas were taken before and after thermomechanical loading (TML; 1.2 Mio cycles; $49 \mathrm{~N} ; 3,000$ thermocycles between $50{ }^{\circ} \mathrm{C}$ and $5{ }^{\circ} \mathrm{C}$ ). Following TML, load was applied until failure. Fracture analysis was performed under a stereomicroscope $(\times 16)$. Marginal quality before and after TML (tooth restoration, composite restoration) was evaluated using scanning electron microscopy $(\times 200)$. RESULTS After TML, lower percentages of continuous margins were observed in groups G1-G3 compared with pre-TML assessments; however, the differences were not statistically significant. For group G4-LAV, the marginal quality after TML was significantly better than in any other group. The highest mean fracture value was recorded for group G4. No significant difference was found for this value between the groups with PBE compared with the groups without PBE, regardless of the material used. The specimens restored with ceramic onlays exhibited fractures that were mainly restricted to the restoration while, in teeth restored with composite onlays, the percentage of catastrophic failures (fractures beyond bone level) was increased. CONCLUSION PBE had no impact on either the marginal integrity or the fracture behavior of root canal-treated mandibular molars restored with feldspathic ceramic onlays. CAD/CAM-fabricated composite onlays were more favorable than ceramic onlays in terms of both marginal quality and fracture resistance, particularly in specimens without PBE. CLINICAL RELEVANCE Composite onlays with or without PBE may be a viable approach for the restoration of root-filled molars with subgingival MOD cavities.
\end{abstract}

DOI: https://doi.org/10.1007/s00784-014-1325-z

Posted at the Zurich Open Repository and Archive, University of Zurich

ZORA URL: https://doi.org/10.5167/uzh-99756

Journal Article

Accepted Version 
Originally published at:

Ilgenstein, Irina; Zitzmann, Nicola U; Bühler, Julia; Wegehaupt, Florian J; Attin, Thomas; Weiger, Roland; Krastl, Gabriel (2015). Influence of proximal box elevation on the marginal quality and fracture behavior of root-filled molars restored with CAD/CAM ceramic or composite onlays. Clinical Oral Investigations, 19(5):1021-1028.

DOI: https://doi.org/10.1007/s00784-014-1325-z 


\section{Influence of proximal box elevation on the marginal quality and fracture behavior of root-filled molars restored with CAD/CAM ceramic or composite onlays}

Irina Ilgenstein ${ }^{1}$, Nicola U Zitzmann ${ }^{1}$, Julia Bühler ${ }^{1}$, Florian J Wegehaupt ${ }^{2}$, Thomas Attin², Roland Weiger ${ }^{1}$, Gabriel Krastl ${ }^{3}$

${ }^{1}$ Department of Periodontology, Endodontology and Cariology, University of Basel, Switzerland

${ }^{2}$ Department of Preventive Dentistry, Periodontology and Cariology, University of Zurich, Switzerland

${ }^{3}$ Department of Operative Dentistry and Periodontology, University of Würzburg, Germany

\section{Corresponding author:}

Irina llgenstein

Dept. of Periodontology, Endodontology and Cariology

University of Basel

Hebelstrasse 3, 4056 Basel (Switzerland)

Tel.: +41-61-2672623

Fax: $\quad+41-61-2672659$

Email: Irina.Ilgenstein@unibas.ch

\section{Abstract}

Objectives This study investigated the influence of proximal box elevation (PBE) with composite resin when applied to deep proximal defects in root-filled molars with MOD cavities, which were subsequently restored with CAD/CAM ceramic or composite restorations.

Materials and methods Root canals treatment was performed on 48 human mandibular molars. Standardized MOD cavities were prepared with the distal box located $2 \mathrm{~mm}$ below the cemento-enamel junction (CEJ). The teeth were randomly assigned to one of four experimental groups $(n=12)$.

In groups G1 and G2, the distal proximal box was elevated up to the level of the CEJ with composite resin (PBE). No elevation was performed in the remaining two groups (G3, G4). CAD/CAM restorations were fabricated with feldspathic ceramic (Vita Mark II, CER) in groups G1 (PBE-CER) and G3 (CER) or with Resin Nano Ceramic blocks (Lava Ultimate, LAV) in groups G2 (PBE-LAV) and G4 (LAV).

Replicas were taken before and after thermomechanical loading (TML; 1.2 Mio cycles; $49 \mathrm{~N}$; 3000 thermocycles between $50^{\circ} \mathrm{C}$ and $5^{\circ} \mathrm{C}$ ). Following $\mathrm{TML}$, load was applied until failure. 
Fracture analysis was performed under a stereomicroscope $(\times 16)$. Marginal quality before and after TML (tooth restoration, composite restoration) was evaluated using scanning electron microscopy (x200).

Results After TML, lower percentages of continuous margins were observed in groups G1G3 compared to pre-TML assessments; however, the differences were not statistically significant. For group G4-LAV, the marginal quality after TML was significantly better than in any other group.

The highest mean fracture value was recorded for group G4. No significant difference was found for this value between the groups with PBE compared to the groups without PBE, regardless of the material used.

The specimens restored with ceramic onlays exhibited fractures that were mainly restricted to the restoration, while in teeth restored with composite onlays, the percentage of catastrophic failures (fractures beyond bone level) was increased.

Conclusion PBE had no impact on either the marginal integrity or the fracture behavior of root canal-treated mandibular molars restored with feldspathic ceramic onlays. CAD/CAMfabricated composite onlays were more favorable than ceramic onlays in terms of both marginal quality and fracture resistance, particularly in specimens without PBE.

Clinical relevance Composite onlays with or without PBE may be a viable approach for the restoration of root-filled molars with subgingival MOD cavities.

Keywords root-filled molars, subgingival margins, proximal box elevation, ceramic onlay, composite onlay, fracture resistance, marginal quality 


\section{Introduction}

It is well known that endodontically treated teeth (ETT) are prone to fracture [1-3]. Multiple reasons for this tendency have been discussed, such as the biomechanical changes that enamel and dentin undergo following endodontic therapy or the loss of substance that occurs during caries removal and cavity preparation $[4,5]$. It has been shown that ETT with mesiooccluso-distal (MOD) preparations display maximal tooth fragility [4-6]. Additionally, greater occlusal loads must be applied to ETT versus their vital opposites before perceived pain triggers load release $[7,8]$. To increase fracture resistance and protect the remaining tooth structure in extended MOD cavities, a restoration with bonded indirect onlays is suggested following cuspal reduction of at least 1.5 to $2 \mathrm{~mm}[2,3,5,6,9]$.

When proximal defects are located in deep sub-gingival areas, cavity preparation, impression taking, and adhesive cementation under dry conditions can be challenging [10-12]. Furthermore, the marginal integrity of these restorations is difficult to control, cement excesses in the sulci are difficult to detect and remove, and interactions with biologic width may occur. Surgical crown lengthening is commonly indicated to preserve healthy periodontal conditions and sufficient dimensions of the junctional epithelium and the supraalveolar connective tissue attachment in such cases [13]. A less invasive alternative procedure involves relocating the proximal cavity margin from an intra-crevicular to a supragingival position using direct composite techniques before placing an indirect restoration [11, $12,14-17]$. This approach is commonly referred to as proximal box elevation (PBE) and is restricted to the comparatively small subgingival area. While it is challenging to perform an adhesive restoration in this region, PBE as a single procedure is still better controlled, and contamination is more easily avoided with PBE, even when rubber dam placement is not feasible [17]. Certainly, this proximal composite resin box has to be plain, smooth and accessible for adequate oral hygiene to be maintained.

Upon relocation of the cavity margins to a supra-gingival position, a sufficient rubber dam application with dry conditions needed for adhesive cementation becomes feasible.

Moreover, this approach avoids bulky restorations, which significantly reduce the access of curing light in deep cavities $[18,19]$. Therefore, PBE may improve light curing and the marginal integrity of indirect restorations. Furthermore, as one of the most critical steps of the cementation procedure, the removal of excess luting composite is better controlled if the margins are relocated supragingivally [14]. The proximal composite base may also reduce the stresses that occur during insertion, polymerization shrinkage or functional loading [20]. According to recent in vitro studies performed on non-endodontically treated molars, PBE did not necessarily influence the marginal adaptation compared to indirect restorations without the placement of a proximal composite base $[11,12,21]$. However, there are currently no 
data available regarding how composite bases in deep sub-gingival areas impact the marginal quality and fracture behavior of root canal filled teeth with indirect restorations.

In recent decades, ceramic has become the material of choice for tooth-colored indirect or semi-direct restorations. While the use of ceramic materials may risk the occurrence of brittle fractures, the recently introduced composite resin blocks for CAD/CAM restorations have several advantages, including low wear rates, favorable aesthetics, cost effectiveness, optimal stiffness, and an elastic modulus similar to dentin [6, 22, 23]. Furthermore, the fracture resistance of the composite resin blocks is greater than that observed for feldspathic ceramic restorations [23-27]. Finally, a finite element model was used to demonstrate that composite resin onlays reduce stress concentrations in ETT due to their lower modulus of elasticity [6].

The aims of the present study were the following: (i) to investigate whether the placement of composite bases into ETT harboring deep proximal defects influences marginal adaptation and fracture resistance following thermo-mechanical stress in molars with CAD/CAM onlays; and, (ii) to analyze how material choice (ceramics vs. composite blocks) impacts fracture behavior.

\section{Materials and Methods}

The study protocol was approved by the local ethics committee (Ethical Committee of Basel, Ref. Nr. EK: 221/12).

\section{Specimen selection and preparation}

Forty-eight human mandibular molars with similar dimensions at the cemento-enamel junction (CEJ), but without any evidence of caries or fractures, were cleaned mechanically with scalers and stored in a $0.1 \%$ thymol solution before further processing. All teeth were randomly assigned to one of four experimental groups ( $G 1$ to $G 4$, each with $n=12$, Fig. 1). Root canal preparation was performed using rotary instruments (Mtwo, VDW, Munich, Germany) up to an apical size of ISO 40 . Sodium hypochlorite (1\%) was used as a root canal irrigant following the use of each instrument. The root canals were filled with vertically condensed gutta-percha (BeeFill, VDW) and an epoxy sealer (AH-Plus ${ }^{\circledR}$, Dentsply De Trey, Konstanz, Germany). The root canal filling was reduced to a level of $1 \mathrm{~mm}$ below the root canal orifice. Water-cooled diamond burs (Inlay-Preparation-Set 4261, Komet, Lemgo, Germany) were used on all specimens to create standardized mesio-occluso-distal (MOD) 
preparations with an occlusal width of half of the intercuspal dimension. The cervical margins were located mesially $1 \mathrm{~mm}$ above the CEJ and distally $2 \mathrm{~mm}$ below the CEJ.

In all the teeth, restoration of the endodontic access cavity was performed with composite resin (Tetric EvoCeram, Ivoclar Vivadent, Schaan, Liechtenstein). Additionally, in half of the specimens $(n=24)$, the distal box was elevated with composite up to the level of the CEJ (G1 and G2). No elevation was performed in the remaining 24 specimens (G3 and G4). For surface conditioning, enamel margins and dentin were etched for $30 \mathrm{~s}$ and $10 \mathrm{~s}$, respectively, with $37 \%$ phosphoric acid (Ultra-etch, Ultradent, Salt Lake City, UT, USA) and rinsed with water for $30 \mathrm{~s}$ before being gently dried with air. A 3-step etch-and-rinse adhesive (Optibond FL, Kerr, Orange, CA, USA) was applied and light cured as recommended by the manufacturer. In groups G1 (PBE-CER) and G2 (PBE-LAV), the deep proximal box in the distal aspect of the tooth was filled up to the level of the CEJ with two 1-mm layers of composite (Tetric EvoCeram). Each layer was light cured separately using a LED curing light (Bluephase G2, Ivoclar Vivadent) for $20 \mathrm{~s}$ at $1200 \mathrm{~mW} / \mathrm{cm}^{2}$. Restoration margins were finished and polished with Sof-Lex discs (3M ESPE, Seefeld, Germany).

For the onlay preparations, a $2 \mathrm{~mm}$ reduction of the buccal and lingual cusps was performed on all teeth. All cavity walls were finished, and sharp inner corners were rounded using a fine diamond bur (4315S, $40 \mu \mathrm{m}$; 5250, $15 \mu \mathrm{m}$, Allround-Set Student Set UNI Basel PEK, Intensiv, Grancia, Switzerland). Optical impressions of the onlay preparations were made with an intraoral camera (CEREC Bluecam, Sirona, Bensheim, Germany). For all specimens, onlays were fabricated with the CEREC 3D system (CEREC AC, software package 4.03).

In groups G1 (PBE-CER) and G3 (CER), the onlay fabrication was performed using feldspathic ceramic blocks (Vita Mark II, Vita Zahnfabrik, Bad Säckingen, Germany). The remaining restorations (G2-PBE-LAV and G4-LAV) were manufactured using composite resin blocks (Lava ${ }^{\mathrm{TM}}$ Ultimate, 3M ESPE).

\section{Luting procedure}

First, $37 \%$ phosphoric acid gel (Ultra-etch, Ultradent) was applied to the enamel for $15 \mathrm{~s}$ before rinsing with water for $10 \mathrm{~s}$. The cavity surface was then gently dried with air for $5 \mathrm{~s}$. A bonding system (Scotchbond Universal Adhesive, 3M Espe) was applied for $20 \mathrm{~s}$ using micro-brushes (Micro-Brush plus, 3M Espe). To avoid generating any detrimental effects to the fit of the restoration, the adhesive was thinned for $5 \mathrm{~s}$ with air to control film thickness. Afterwards, the tooth surfaces were light cured for $20 \mathrm{~s}$ using a light curing unit set at $1200 \mathrm{~mW} / \mathrm{cm}^{2}$ (Bluephase G2, Ivoclar Vivadent). 
The internal surfaces of the ceramic onlays (G1-PBE-CER and G3-CER) were etched with 9.5\% hydrofluoric acid (Porcelain Etch, Ultradent) for $60 \mathrm{~s}$, rinsed with water for $15 \mathrm{~s}$ and dried with air for $20 \mathrm{~s}$. The intaglio surfaces of the composite restorations (G2-PBE-LAV and G4-LAV) were silicatized (Cojet System, 3M Espe). The bonding system (Scotchbond Universal Adhesive, 3M Espe) was then applied to all 48 internal surfaces for $20 \mathrm{~s}$ and dried with air for $5 \mathrm{~s}$ without light curing. The onlays were cemented with RelyX Ultimate (3M Espe). Under continuous pressure, excess luting material was removed with a polyurethane foam pellet (Pele Tim $®$, Voco $\mathrm{GmbH}$, Cuxhaven, Germany). To prevent the formation of an oxygen-inhibited layer, the restoration margins were covered with a water-based glycerinegel (Airblock, DeTrey-Dentsply). Light curing was performed from the mesial, distal, buccal, lingual and occlusal directions for $20 \mathrm{~s}$ each at $1200 \mathrm{~mW} / \mathrm{cm}^{2}$ (Bluephase G2). The restorations were finished with diamond burs (4205L, Intensiv) and polishing discs (Soflex) under an operating microscope at a magnification of $\times 10$ (OPMI pico, Carl Zeiss, Oberkochen, Germany).

\section{Thermomechanical loading (TML)}

The roots of all specimens were coated with a 0.3-mm gum resin layer (Anti-Rutsch-Lack, Wenko-Wenselaar, Hilden, Germany) to simulate a periodontal ligament. The roots were subsequently embedded in self-curing acrylic resin (Demotec 20, Demotec Siegfried Demel, Nidderau, Germany) such that the restoration margins were located approximately $3 \mathrm{~mm}$ above the feigned bone level.

All specimens were loaded with repeated thermal and mechanical stress using a computercontrolled masticator (CoCoM 2, PPK, Zürich, Switzerland) for 1.2 Mio cycles with $49 \mathrm{~N}$ at $1.7 \mathrm{~Hz}$ with cusps of human molars as antagonists. Thermal stress was applied simultaneously via 3000 thermocycles between $5^{\circ} \mathrm{C}$ and $50^{\circ} \mathrm{C}$. These conditions are considered to simulate approximately 5 years of clinical service [28].

\section{Load to fracture}

To determine the fracture behavior and fracture patterns of the samples, all specimens were tested using a universal testing machine (Zwick, Ulm, Germany). Specimens were fixed in a metal holder, and a 6-mm diameter steel sphere was positioned on the central fossa at an angle of $15^{\circ}$ relative to the long axis of the tooth. To avoid excessive stress concentrations at the tooth surface, aluminum foil (0.5-mm thickness) was placed between the onlay surface and the steel sphere. The load was applied at a cross-head speed of $0.5 \mathrm{~mm} / \mathrm{min}$ until failure.

\section{Fracture analysis}


All specimens were meticulously examined under a stereomicroscope (Wild-Heerbrugg AG, Heerbrugg, Switzerland) at a magnification of $x 16$ to obtain a detailed failure analysis. The fracture lines of each specimen were identified and categorized into three patterns: (1) fractures affecting solely the restoration, (2) fractures affecting both the restoration and the tooth above the simulated bone level, and (3) fractures affecting both the restoration and the tooth below the feigned bone level. The latter failure type was judged to be non-restorable, while categories 1 and 2 were deemed to be restorable fracture modes. Each specimen was investigated from five sides (buccal, lingual, mesial, distal, and occlusal), and any visible fracture line was illustrated on a schematic according to its direction and position.

\section{Quantitative marginal analysis}

Pre- and post-TML crown impressions were made using polyvinyl-siloxane (President light body, Coltène, Altstätten, Switzerland), and epoxy resin replicas (Stycast 1266, Emerson \& Cuming, Westerlo, Belgium) were fabricated and sputter-coated with gold (Sputer SCD 030, Balzers Union, Balzers, Liechtenstein). A quantitative marginal analysis was performed on the distal box of each specimen by an experienced examiner using a scanning electron microscope (Amray 1810/T, Amray, Bedford, MA) set at $10 \mathrm{kV}$ and x200 magnification.

Marginal integrity was evaluated at two different interfaces (Fig. 2). The first interface ('toothcomposite') was located between the cervical tooth structure and the composite margin (either the material used for PBE or the luting composite in groups without PBE). The second interface was located between the ceramic/composite onlay and the luting composite ('onlay-luting composite'). The marginal quality was classified as 'continuous' (no gap), 'noncontinuous' (gap or interruption of continuity, fractures related to restoration margins), and 'not judgeable/artifact'. Finally, the percentage of continuous margin within each specimen was calculated and presented as a percentage of the individual judgeable margin.

\section{Statistical analysis}

Statistical evaluation was performed with JMP 9 software (SAS Institute, Cary, NC, USA). Descriptive statistical calculations were performed to generate means and standard deviation. The data from the fracture resistance tests were graphically displayed as box \& whisker plots. The fracture loads were investigated by one-way analysis of variance (ANOVA) followed by multiple comparisons using Tukey's post hoc test. Values of $p<0.05$ were accepted as statistically significant.

Mean values and confidence intervals were calculated for the marginal adaptation scores in each group. Groups were considered significantly different when the confidence intervals did not overlap. 


\section{Results}

\section{Marginal quality}

Prior to TML, a significantly higher percentage of continuous margins were detected in G4LAV compared to G1-PBE-CER and G3-CER at the 'tooth-composite' interface (Table 1). After TML, lower percentages of continuous margins were observed in groups G1, G2 and G3 compared to the pre-TML assessment, but these differences were not statistically significant. In group G4 (LAV), the marginal quality after TML was significantly better than that measured for any other group but did not differ from the pre-TML assessment.

A significant reduction in marginal quality was detected at the 'onlay-luting composite' interface following TML in specimens restored with ceramic onlays (G1-PBE-CER), while no significant difference was observed for teeth restored with composite onlays (G2-PBE-LAV, Table 2).

\section{TML and load-to-fracture test}

The highest mean fracture value was recorded for G4-LAV and was significantly different from that recorded for G3-CER $(p=0.0053)$. Groups $\mathrm{G} 1$ and $\mathrm{G} 2$, which had undergone proximal box elevation, revealed similar values regardless of the material used (Fig. 3).

Specimens restored with ceramic onlays (G1 and G3) predominantly exhibited fractures solely within the restoration, while in teeth restored with composite onlays (G2 and G4), the percentage of catastrophic failures increased. In groups G1, G2 (with PBE) and G4 (no $\mathrm{PBE}$ ), all fractures on the distal aspect of the tooth had a vertical orientation, while in group $\mathrm{G} 3$, horizontal fractures of the ceramic restoration at the level of the cuspal reduction were observed in 4 out of 12 specimens (Table 3; Fig. 4).

\section{Discussion}

This study was conducted to investigate how proximal box elevation (PBE) and the use of different restoration materials influences the marginal adaptation and fracture behavior of root-filled molars with MOD cavities. It was demonstrated that PBE did not impact fracture resistance regardless of the material used. Overall, composite restorations exhibited better marginal integrity and higher fracture resistance compared to ceramic onlays.

In the current study, the relocation of deep cavity margins was performed using two layers of a bonded hybrid composite resin based on the results of a recently published study, which demonstrated that a meticulous layering technique with a hybrid material is the best way to counteract gap formation [11]. The concept of coronal relocation of cavity margins extending 
cervically into the dentin structure was first proposed by Dietschi \& Spreafico [14] to simplify the clinical procedure of adhesive cementation. Different materials such as resin-modified glass ionomers, compomers and flowable composites were considered for use in this approach. Controversy exists regarding whether material properties can influence marginal and internal adaptation in the area surrounding PBE. Dietschi et al. [10] found that materials with an intermediate elastic modulus such as flowable composites had a more favorable marginal adaptation compared to rigid materials, while Rocca et al. [21] found that composite type exerted no significant influence on marginal adaptation. Furthermore, the application of three consecutive 1-mm-thick layers of a highly filled restorative composite provided the best marginal quality to dentin, whereas self adhesive resin cements performed significantly more poorly [11]. In accordance with these results, a recent study discussed the benefit of highly filled composites for PBE due to their lower contraction stress during polymerization and higher resistance to deformation under load compared to materials with a lower modulus of elasticity [12].

In the present study, teeth with composite onlay restorations and PBE showed a poorer marginal integrity at the dentin interface following TML compared to specimens without PBE. PBE was not found to influence the marginal quality of the specimens restored with ceramic onlays, while fracture resistance seemed to be slightly increased (though this increase was found to be insignificant). Accordingly, other studies have shown that the PBE approach has no adverse effect on the marginal integrity of dentin [11,12]. The increased fracture resistance is most likely related to the reduced extension of the proximal wing causing different stress patterns on the restored tooth [29]. Among the ceramic specimens, PBE led to vertical fracture lines only, while restorations without PBE exhibited horizontal fracturing of the distal proximal wing at the level of the cuspal coverage. These findings may be due to a combination of an unfavorable cavity design with a greater concentration of tensile stress at the transition between the occlusal and proximal boxes and the rigidity of the ceramic material.

Overall, the present results revealed a considerably greater percentage of perfect margins at both interfaces and higher fracture resistance for composite onlays compared to feldspathic ceramic restorations. These findings are in accordance with previous data comparing the two materials [6, 24, 30-32]. The marginal adaption of crowns fabricated from composite blocks was found to be better compared to ceramic crowns in endodontically treated teeth [33]. Obviously the higher resilience of the composite material attenuates the stress transferred to the restoration margins. Composite resins possess mechanical characteristics similar to dentin that might reduce the stress generated in the residual hard tissue [6]. Lin et al. [24] 
showed that large ceramic restorations exhibit higher stress levels and that the use of materials with a lower elastic modulus like composite resins limits the stress intensity transmitted to the remaining tooth structure. Another current study showed that composite resin restorations produced the most favorable stress distribution pattern in MOD cavity restorations of both vital and endodontically treated teeth [6].

The present study demonstrated that the type of material used to restore teeth influenced the proportion of catastrophic versus repairable fractures. The latter were more frequent among the specimens restored with ceramic onlays and were located within the restoration in the majority of cases. This is in agreement with previous data showing that teeth restored with feldspathic ceramic tend to have less severe fractures that do not involve the tooth structure itself, in contrast to bonded composite restorations [34]. Ceramic restorations tend to concentrate more stress inside the restoration whereas composite resins transfer more stress to the tooth structure [35].

In general, extrapolating from in vitro data to draw conclusions regarding the clinical performance of restorations of ETT must be performed with caution. The majority of in vitro studies performed to date have only evaluated the maximum load capability of tooth specimens, and extrapolating the observations made during destructive testing to clinical conclusions is not realistic. Artificial ageing is known to have a considerable impact on the data generated in load-to-fracture tests [36]. For this reason, an experimental design combining cyclic loading within physiological limits and simultaneous thermocycling was used in the present study. Furthermore, the periodontal ligament was simulated to more accurately mimic the oral cavity $[37,38]$.

Against this background and considering further variations of the experimental design in the different studies, such as cross-head speed and load angle, a comparison of the absolute values generated in the present load to fracture test with those obtained in other studies is not feasible.

\section{CONCLUSION}

PBE does not negatively influence the marginal integrity or fracture behavior of root canaltreated mandibular molars restored with feldspathic ceramic onlays. In particular, CAD/CAMfabricated composite onlays without PBE are more favorable in terms of marginal quality and fracture resistance than are ceramic restorations.

\section{Conflict of interest}

The authors have no conflict of interest related to this study. 


\section{Acknowledgements}

The authors are grateful to Svend Galli (Basel) and Lars Tuchel (Zurich) for their valuable help with the chewing simulator and the SEM analysis, respectively.

Figure and Table Legends

Fig. 1 Overview of the study design

Fig. 2 Interfaces evaluated for marginal integrity

Interface 1: 'Tooth-composite' (green line) between the cervical tooth structure and the composite material used for the elevation of the proximal box ( $G 1$ and G2) or the luting composite (G3 and G4).

Interface 2: 'Onlay-luting composite' (blue line) between the ceramic/composite onlay and the luting composite (G1 and G2).

Fig. 3 Box-and-whisker plots of the fracture load for each group (in Newtons).

Fig. 4 Detailed failure modes of each experimental group, summarizing the main fractures (red lines) and cracks (black lines).

Table 1 Percentage of continuous margins at the interface 'tooth-composite' before and after TML.

Table 2 Percentage of continuous margins at the interface 'Onlay-luting composite' before and after TML.

Table 3 Results of the load-to-fracture test in the four experimental groups: mean load capability values in N, standard deviation (SD), confidence intervals $(\mathrm{CI})$ and fracture modes. 


\section{References}

1. Adolphi G, Zehnder M, Bachmann LM and Gohring TN (2007) Direct resin composite restorations in vital versus root-filled posterior teeth: a controlled comparative long-term follow-up. Oper Dent 32:437-442

2. Wendt SL Jr., Harris BM and Hunt TE (1987) Resistance to cusp fracture in endodontically treated teeth. Dent Mater 3:232-235

3. Magne $P$ and Knezevic A (2009) Thickness of CAD-CAM composite resin overlays influences fatigue resistance of endodontically treated premolars. Dent Mater 25:12641268

4. Dietschi D, Duc O, Krejci I and Sadan A (2007) Biomechanical considerations for the restoration of endodontically treated teeth: a systematic review of the literature-Part 1. Composition and micro- and macrostructure alterations. Quintessence Int 38:733-743

5. ElAyouti A, Serry MI, Geis-Gerstorfer J and Lost C (2011) Influence of cusp coverage on the fracture resistance of premolars with endodontic access cavities. Int Endod J 44:543549

6. Jiang W, Bo H, Yongchun $G$ and LongXing N (2010) Stress distribution in molars restored with inlays or onlays with or without endodontic treatment: a three-dimensional finite element analysis. J Prosthet Dent 103:6-12

7. Hitz T, Ozcan M and Gohring TN (2010) Marginal adaptation and fracture resistance of root-canal treated mandibular molars with intracoronal restorations: effect of thermocycling and mechanical loading. J Adhes Dent 12:279-286

8. Randow K and Glantz PO (1986) On cantilever loading of vital and non-vital teeth. An experimental clinical study. Acta Odontol Scand 44:271-277

9. Dietschi D, Duc O, Krejci I and Sadan A (2008) Biomechanical considerations for the restoration of endodontically treated teeth: a systematic review of the literature, Part II (Evaluation of fatigue behavior, interfaces, and in vivo studies). Quintessence Int 39:117129

10. Dietschi D, Olsburgh S, Krejci I and Davidson C (2003) In vitro evaluation of marginal and internal adaptation after occlusal stressing of indirect class II composite restorations with different resinous bases. Eur J Oral Sci 111:73-80

11. Frankenberger R, Hehn J, Hajto J, Kramer N, Naumann M, Koch A and Roggendorf MJ (2013) Effect of proximal box elevation with resin composite on marginal quality of ceramic inlays in vitro. Clin Oral Investig 17:177-183

12. Zaruba M, Gohring TN, Wegehaupt FJ and Attin T (2013) Influence of a proximal margin elevation technique on marginal adaptation of ceramic inlays. Acta Odontol Scand 71:317-324

13. Schmidt JC, Sahrmann P, Weiger R, Schmidlin PR and Walter C (2013) Biologic width dimensions-a systematic review. J Clin Periodontol 40:493-504

14. Dietschi D and Spreafico R (1998) Current clinical concepts for adhesive cementation of tooth-colored posterior restorations. Practical periodontics and aesthetic dentistry : PPAD 10:47-54; quiz 56

15. Rocca GT and Krejci I (2007) Bonded indirect restorations for posterior teeth: the luting appointment. Quintessence Int 38:543-553

16. Rocca GT and Krejci I (2007) Bonded indirect restorations for posterior teeth: from cavity preparation to provisionalization. Quintessence Int 38:371-379

17. Frese C, Wolff D and Staehle HJ (2014) Proximal box elevation with resin composite and the dogma of biological width: clinical R2-technique and critical review. Oper Dent 39:22-31

18. Chan KC and Boyer DB (1989) Curing light-activated composite cement through porcelain. J Dent Res 68:476-480

19. El-Mowafy OM and Rubo MH (2000) Influence of composite inlay/onlay thickness on hardening of dual-cured resin cements. J Can Dent Assoc 66:147 
20. Lutz F, Krejci I and Oldenburg T (1986) Elimination of polymerisazion stresses at the margins of posterior composite resin restorations: a new restorative technique. Quintessence Int 17:777-784

21. Rocca GT, Gregor L, Sandoval MJ, Krejci I and Dietschi D (2012) In vitro evaluation of marginal and internal adaptation after occlusal stressing of indirect class II composite restorations with different resinous bases and interface treatments. "Post-fatigue adaptation of indirect composite restorations". Clin Oral Investig 16:1385-1393

22. Attia A, Abdelaziz KM, Freitag $S$ and Kern M (2006) Fracture load of composite resin and feldspathic all-ceramic CAD/CAM crowns. J Prosthet Dent 95:117-123

23. Rocca GT, Bonnafous F, Rizcalla N and Krejci I (2010) A technique to improve the esthetic aspects of CAD/CAM composite resin restorations. J Prosthet Dent 104:273275

24. Lin CL, Chang YH and Liu PR (2008) Multi-factorial analysis of a cusp-replacing adhesive premolar restoration: A finite element study. J Dent 36:194-203

25. Magne $P$ and Knezevic A (2009) Simulated fatigue resistance of composite resin versus porcelain CAD/CAM overlay restorations on endodontically treated molars. Quintessence Int 40:125-133

26. Magne P, Schlichting LH, Maia HP and Baratieri LN (2010) In vitro fatigue resistance of CAD/CAM composite resin and ceramic posterior occlusal veneers. J Prosthet Dent 104:149-157

27. Schlichting LH, Maia HP, Baratieri LN and Magne $P$ (2011) Novel-design ultra-thin CAD/CAM composite resin and ceramic occlusal veneers for the treatment of severe dental erosion. J Prosthet Dent 105:217-226

28. Lambrechts P, Debels E, Van Landuyt K, Peumans M and Van Meerbeek B (2006) How to simulate wear? Overview of existing methods. Dent Mater 22:693-701

29. Liu X, Fok A and Li H (2014) Influence of restorative material and proximal cavity design on the fracture resistance of MOD inlay restoration. Dent Mater 30:327-333

30. Dere M, Ozcan M and Gohring TN (2010) Marginal quality and fracture strength of rootcanal treated mandibular molars with overlay restorations after thermocycling and mechanical loading. J Adhes Dent 12:287-294

31. Dalpino PH, Francischone CE, Ishikiriama A and Franco EB (2002) Fracture resistance of teeth directly and indirectly restored with composite resin and indirectly restored with ceramic materials. Am J Dent 15:389-394

32. Bortolotto T, Onisor I and Krejci I (2007) Proximal direct composite restorations and chairside CAD/CAM inlays: marginal adaptation of a two-step self-etch adhesive with and without selective enamel conditioning. Clin Oral Investig 11:35-43

33. Ramirez-Sebastia A, Bortolotto T, Roig M and Krejci I (2013) Composite vs ceramic computer-aided design/computer-assisted manufacturing crowns in endodontically treated teeth: analysis of marginal adaptation. Oper Dent 38:663-673

34. Soares CJ, Martins LR, Pfeifer JM and Giannini M (2004) Fracture resistance of teeth restored with indirect-composite and ceramic inlay systems. Quintessence Int 35:281286

35. Costa A, Xavier T, Noritomi P, Saavedra G and Borges A (2014) The influence of elastic modulus of inlay materials on stress distribution and fracture of premolars. Oper Dent 39:E160-170

36. Sterzenbach G, Rosentritt M, Frankenberger R, Paris S and Naumann M (2012) Loading standardization of postendodontic restorations in vitro: impact of restorative stage, static loading, and dynamic loading. Oper Dent 37:71-79

37. Brosh T, Porat N, Vardimon AD and Pilo R (2011) Appropriateness of viscoelastic soft materials as in vitro simulators of the periodontal ligament. J Oral Rehabil 38:929-939

38. Brosh T, Zary R, Pilo R and Gavish A (2012) Influence of periodontal ligament simulation and splints on strains developing at the cervical area of a tooth crown. Eur $\mathrm{J}$ Oral Sci120:466-471 


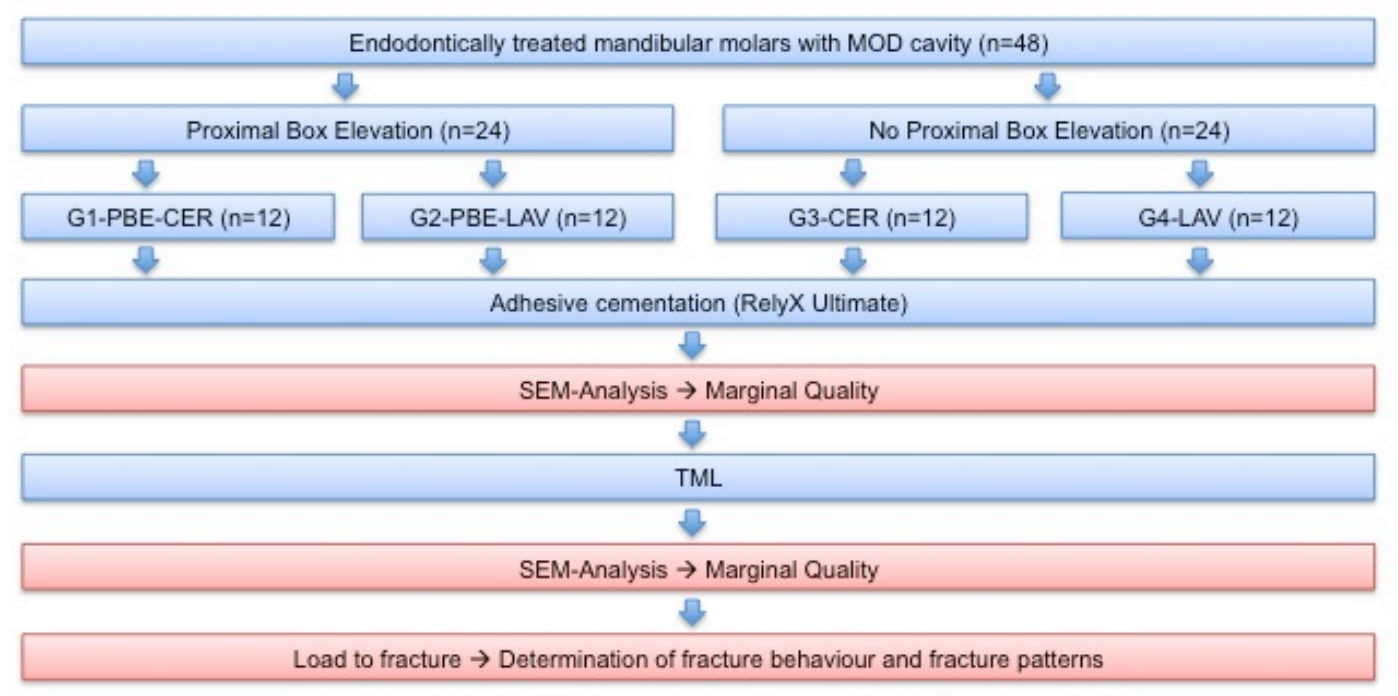

Fig. 1 Overview of the study design 


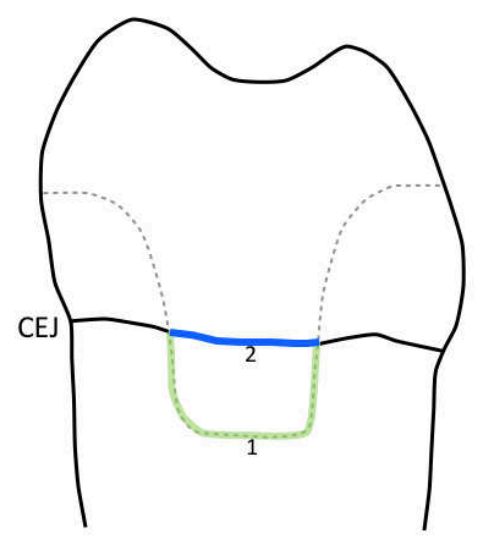

Fig. 2 Interfaces evaluated for marginal integrity

Interface 1: 'Tooth-composite' (green line) between the cervical tooth structure and the composite material used for the elevation of the proximal box (G1 and G2) or the luting composite (G3 and G4). Interface 2: 'Onlay-luting composite' (blue line) between the ceramic/composite onlay and the luting composite (G1 and G2). 


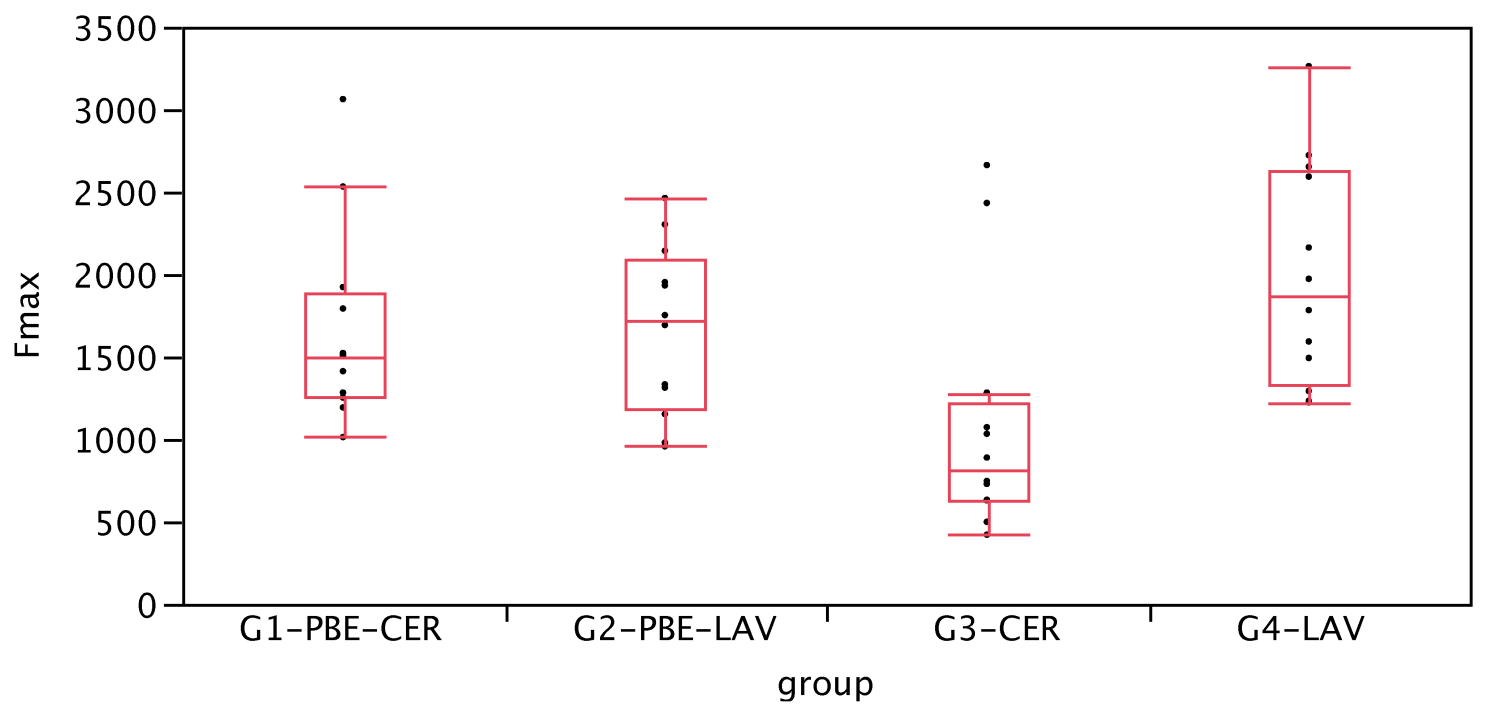

Fig. 3 Box-and-whisker plots of the fracture load for each group (in Newtons). 

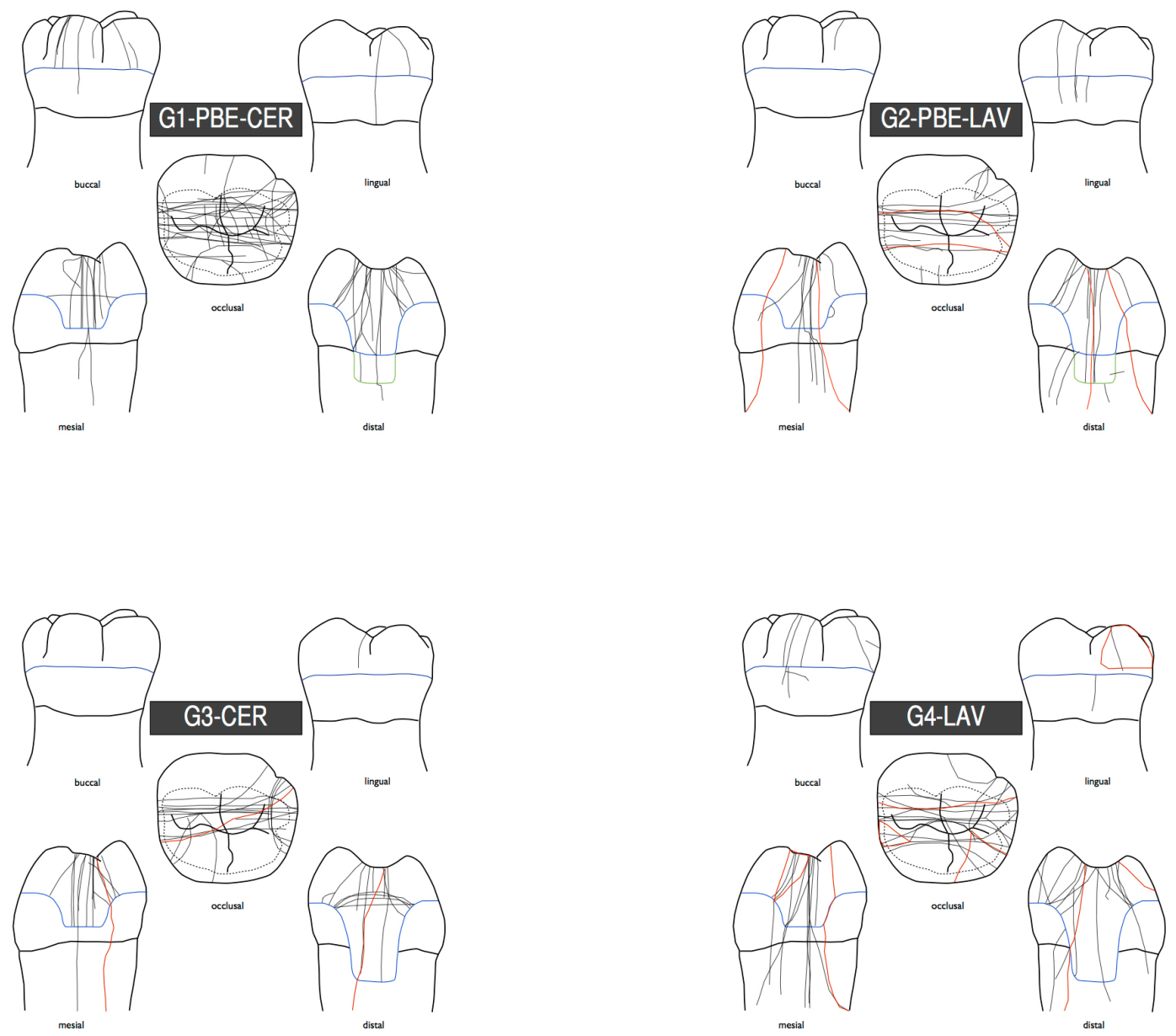

Fig. 4 Detailed failure modes of each experimental group, summarizing the main fractures (red lines) and cracks (black lines). 
Table 1 Percentage of continuous margins at the interface 'tooth-composite' before and after TML.

\begin{tabular}{|l|c|r|c|c|}
\hline Group & \multicolumn{2}{|c|}{ Before TML } & \multicolumn{2}{c|}{ After TML } \\
\hline & Mean & $\mathbf{9 5 \%}$ Cl & Mean & $\mathbf{9 5 \%}$ Cl \\
\hline G1-PBE-CER & $81.4^{\mathrm{C}}$ & $72.7 ; 90.1$ & $64.6^{\mathrm{C}}$ & $46.6 ; 82.6$ \\
\hline G2-PBE-LAV & $91.9^{\mathrm{BC}}$ & $87.7 ; 96.1$ & $80.1^{\mathrm{C}}$ & $67.9 ; 92.2$ \\
\hline G3-CER & $81.6^{\mathrm{C}}$ & $72.9 ; 90.3$ & $69.8^{\mathrm{C}}$ & $61.4 ; 78.1$ \\
\hline G4-LAV & $97.5^{\mathrm{AB}}$ & $95.7 ; 99.2$ & $98.4^{\mathrm{A}}$ & $97.2 ; 99.6$ \\
\hline
\end{tabular}

A significant difference between two groups exists when the confidence intervals do not overlap. Groups indicated with the same superscript letter were not significantly different. 
Table 2 Percentage of continuous margins at the interface 'Onlay-luting composite' before and after TML.

\begin{tabular}{|l|c|c|c|c|}
\hline Group & \multicolumn{2}{|c|}{ Before TML } & \multicolumn{2}{c|}{ After TML } \\
\hline & Mean & $\mathbf{9 5 \%}$ Cl & Mean & $\mathbf{9 5 \%}$ Cl \\
\hline G1-PBE-CER & $89.5^{A}$ & $79.1 ; 100$ & $46.9^{B}$ & $31.3 ; 62.6$ \\
\hline G2-PBE-LAV & $98.5^{A}$ & $97.7 ; 99.4$ & $95.2^{A}$ & $91.8 ; 98.6$ \\
\hline
\end{tabular}

A significant difference between two groups exists when the confidence intervals do not overlap. Groups indicated with the same superscript letter were not significantly different. 
Table 3 Results of the load-to-fracture test in the four experimental groups: mean load capability values in $\mathrm{N}$, standard deviation (SD), confidence intervals $(\mathrm{Cl})$ and fracture modes.

\begin{tabular}{|l|r|r|l|l|l|}
\hline Groups & Mean (SD) & $\mathbf{9 5 \%}$ Cl & $\begin{array}{l}\text { Fracture Mode 1 } \\
\text { (within the } \\
\text { restoration) }\end{array}$ & $\begin{array}{l}\text { Fracture Mode 2 } \\
\text { (restoration and tooth, } \\
\text { above bone level) }\end{array}$ & $\begin{array}{l}\text { Fracture Mode 3 } \\
\text { (catastrophic; below } \\
\text { bone level) }\end{array}$ \\
\hline G1-PBE-CER & $1664.2(594.5)^{\mathrm{AB}}$ & $1286.5 ; 2041.9$ & 10 & 1 & 1 \\
\hline G2-PBE-LAV & $1661.8(513.7)^{\mathrm{AB}}$ & $1335.4 ; 1988.1$ & 7 & 2 & 3 \\
\hline G3-CER & $1083.0(727.7)^{\mathrm{B}}$ & $620.6 ; 1545.4$ & 10 & 0 & 2 \\
\hline G4-LAV & $1995.8(679.9)^{\mathrm{A}}$ & $1563.8 ; 2427.8$ & 4 & 2 & 6 \\
\hline
\end{tabular}

Groups indicated with the same superscript letter were not significantly different. 